\title{
Practical pediatric nephrology
}

\section{Hemodialysis in infants and small children}

\author{
Raymond A. Donckerwolcke ${ }^{1}$ and Timothy E. Bunchman ${ }^{2}$ \\ ${ }^{1}$ Wilhelmina Children's Hospital, Postbus 18009, 3501 CA Utrecht, The Netherlands \\ 2 C. S. Mott Children's Hospital, The University of Michigan Medical Center, Box 0297-L2602, 1521 Simpson Road East, Ann Arbor, MI 48109, USA
}

Received June 1, 1993; accepted June 15, 1993

\begin{abstract}
Hemodialysis in infants and small children requires specialized nursing staff, equipment and adequate access. The techniques, requirements and available equipment for this population are discussed.
\end{abstract}

Key words: Hemodialysis - Heparin - Ultrafiltration Extracorporeal circuit

\section{Introduction}

Several reports on hemodialysis (HD) in infants and small children were published during the 1970s, but during the last decade continuous peritoneal dialysis (PD) has become the modality of choice in the majority of small children with end-stage renal disease (ESRD) [1, 2]. However, between 1986 and 1988 in Europe and the United States, in $10 \%-30 \%$ of all children with ESRD less than 2 years of age, HD was the first method of renal replacement therapy $[3,4]$.

For chronic dialysis, the perference of parents and treatment team will most often determine the choice of PD or HD, but medical problems (ileostomy, ureterocutaneostomy, chronic pulmonary disease) may indicate the choice of HD. For dialysis in acute renal failure in infants, HD is preferred over PD in patients with recent abdominal surgery, peritoneal pleural leaks, colitis and severe pulmonary disease. Further more, some endogenous (hyperammonemia) and exogenous (methanol, ethylene glycol) intoxications are more efficiently treated by HD than by other methods of renal replacement [5].

While basic principles and procedures of HD are similar in all age groups, adaptation of commercially available equipment to the size of the infant is unsatisfactory; therefore, modifications in technique are required to perform

Correspondence to: T. E. Bunchman
$\mathrm{HD}$ in infants without major complications. In this paper, available and adapted methods for the treatment of small children are discussed.

\section{Vascular access}

For emergency HD, a simple, immediately usable, vascular access is required. Newborn infants can be dialyzed via the umbilical vein using a 5.0 - to 8.5 -Fr umbilical venous catheter. In older children, the percutaneous cannulation of the femoral vein is the method of choice. One or two femoral veins are cannulized by the Seldinger technique. When two catheters are to be inserted in small children, it is easier to catheterize each femoral vein instead of insertion of both catheters on the same side. One catheter is advanced into the inferior vena cava ("venous" infusion), while the other is positioned in the internal iliac vein ("arterial" draw). This decreases the amount of recirculation that could occur if the tips of both accesses were adjacent to each other. With polyurethane catheters with an internal diameter of at least $1.3 \mathrm{~mm}$, appropriate blood flows may be achieved.

Femoral catheterization is useful when only a few dialyses are necessary. For prolonged treatment, a silicone catheter (Hickman) introduced through a jugular or subclavian vein, with the tip positioned in the right atrium, should be used [6]. In children weighing less than $15 \mathrm{~kg}$, efficient dialysis using a single-lumen catheter $(9.6 \mathrm{Fr}$ ) with an internal diameter of $1.6 \mathrm{~mm}$ and a single-needle system can be performed (Bard-Hickman catheter).

In larger children, dual-lumen Hickman (10 and $12 \mathrm{Fr}$ ) or Pediatric Quinton Permcath (14 Fr) catheters with a lumen size of 1.3 or $1.6 \mathrm{~mm}$ each are preferred. Blood flow rates of $25-50 \mathrm{ml} / \mathrm{min}$ with single-lumen and of 50$100 \mathrm{ml} / \mathrm{min}$ with dual-lumen catheters are achieved. Both the Hickman as well as the Quinton catheters are cuffed, allowing for a "seal" to occur in the subcutaneous tissue, resulting in long-term accessibility.

Between dialysis treatments, the catheter may be used for parenteral nutrition or measurements of central venous 
Table 1. Disposable dialyzers for use in small children $(<20 \mathrm{~kg})$

\begin{tabular}{|c|c|c|c|c|c|c|}
\hline & \multirow[t]{2}{*}{ Dialyzer } & \multicolumn{2}{|l|}{ Membrane } & \multirow{2}{*}{$\begin{array}{l}\text { Priming volume } \\
(\mathrm{ml})\end{array}$} & \multicolumn{2}{|l|}{ Ultrafiltration } \\
\hline & & Composition & $\mathrm{SA}^{\mathrm{a}}\left(\mathrm{m}^{2}\right)$ & & $\begin{array}{l}\text { compliance } \\
(\mathrm{ml} / 100 \mathrm{mmHg})\end{array}$ & $\begin{array}{l}\text { coefficient } \\
(\mathrm{ml} / \mathrm{h} \text { per } \mathrm{mmHg} \mathrm{TMP})^{\mathrm{b}}\end{array}$ \\
\hline \multicolumn{7}{|l|}{ Europe } \\
\hline & Asahi AM 0.3 & Cuprammonium & 0.3 & 30 & 0 & 1.4 \\
\hline & Fresenius F3 & Polysulfone & 0.4 & 30 & 0 & 1.7 \\
\hline & Gambro Pro 100 & Polycarbonate & 0.3 & 19 & 6 & 2.2 \\
\hline \multicolumn{7}{|l|}{ USA } \\
\hline & Gambro MiniMinor & Cuprophane & 0.28 & 20 & 6 & 0.5 \\
\hline & Gambro-1C-1L & Cuprophane & 0.28 & 32 & 10 & 0.62 \\
\hline & Gambro $1 \mathrm{C}-1 \mathrm{~N}$ & Cuprophane & 0.4 & 43 & 10 & 1 \\
\hline & Gambro-1C-1H & Cuprophane & 0.4 & 47 & 10 & 1.5 \\
\hline & Gambro CA-50 & Cellulase acetate & 0.5 & 38 & 0 & 2.4 \\
\hline & Cobe HG-100 & Hemophan & 0.22 & 18 & 0 & 2.0 \\
\hline
\end{tabular}

a SA, Surface area

b TMP, transmembrane pressure

Table 2. Available hemodialysis machines with neonatal or pediatric lines in the United States and Europe

\begin{tabular}{llll}
\hline Company & Single needle? & $\begin{array}{l}\text { Neonatal, arterial } \\
\text { and venous } \\
\text { lines (ml) }\end{array}$ & $\begin{array}{l}\text { Pediatric, arterial } \\
\text { and venous } \\
\text { lines (ml) }\end{array}$ \\
\hline Gambro AK10 & Yes & 32 & 70 \\
Baxter SPS 550 & No & $20^{\mathrm{a}}$ & $62^{\mathrm{b}}$ \\
Cobe Century 3 & Yes & 40 & 80 \\
Fresenius & Yes & 20 & 62 \\
\hline
\end{tabular}

a Made be Life Med

b Made by Fresenius

pressure. If not used between dialysis, a 3-ml heparinized saline (100:1 concentration) is injected into the Hickman catheter and a cap is placed at the external end. The Quinton Permcath is heparinized with $1.1 \mathrm{ml}$ to each port of 1,000:1 concentration heparin. Please note that specific heparinization is directed toward the volume and the coagulability of the catheter, not the patient.

Important immediate complications of catheter placement are perforation of the veins with development of pneumothorax or pneumomediastinum and hemothorax or hemomediastinum, while a late complication is vascular obstruction mainly confined to the side of vessel penetration [7]. The occurrence of catheter obstruction and infection is dependent on the attention and care given to the access.

\section{Extracorporeal circuit}

The rule that the volume of the extracorporeal blood circuit should never exceed $10 \%$ of the patient's blood volume ( $80 \mathrm{ml} / \mathrm{kg}$ body weight) is generally accepted. As this is difficult to achieve in infants, either single-needle HD or a dual lumen with the smaller extracorporeal lines and dialyzers may aid in achieving this goal (Tables 1,2). This is seldom achieved in a child weighing less than $8 \mathrm{~kg}$. The blood content of the catheters and Y-tubing (single needle)
Table 3. Urea clearances disposable dialyzers

\begin{tabular}{lllllll}
\hline & \multicolumn{5}{c}{$\begin{array}{l}\text { Urea clearances at blood flow rates } \\
(\mathrm{m} / \mathrm{min})^{\mathrm{a}}\end{array}$} \\
\cline { 3 - 7 } & & 50 & 75 & 100 & 125 & 150 \\
\hline Europe & & & & & & \\
& & & & & \\
& Asahin AM 0.3 & 45 & -- & 64 & -- & 68 \\
& Fresenius F3 & 45 & 63 & 78 & 89 & 98 \\
& Gambro Pro 100 & 51 & 50 & 54 & 59 & 66 \\
USA & & & & & \\
& Gambro & 38 & -- & 51 & -- & 57 \\
& Mini Minor & & & & & \\
& Gambro 1C-1L & 36 & -- & 50 & -- & 56 \\
& Gambro 1C-1N & 46 & -- & 76 & -- & 91 \\
& Gambro 1C-1H & 48 & -- & 78 & -- & 93 \\
& Gambro CA-50 & 55 & -- & 90 & -- & 105 \\
& Cobe HG10 & 50 & -- & 80 & -- & 102 \\
\hline
\end{tabular}

a In vivo measurements

ranges from 2 to $5 \mathrm{ml}$. The bloodlines for use in very small children have a priming volume ranging from 20 to $80 \mathrm{ml}$ (Table 2). The internal diameter of these tubings varies from 1.5 to $3 \mathrm{~mm}$ and will restrict blood flows respectively to 30 and $75 \mathrm{ml} / \mathrm{min}$. When a single-needle system with an alternating clamp is used, an additional expansion chamber is required $(10 \mathrm{ml})$. Compliance is possible within the plate dialyzer but not in the hollow-fiber dialyzer. Some institutions have utilized the venous drip chamber as the "compliant" chamber in conjunction with a hollow fiber dialyzer, yet no pediatric data are available using this approach.

In Europe, commercially available hollow-fiber dialyzers (Asahi 0.3 and Fresenius F3) have a blood content of $30 \mathrm{ml}$. The Gambro plate dialyzer (Pro 100) has a priming volume of $19 \mathrm{ml}$, increasing to $30 \mathrm{ml}$ at a transmembrane pressure of $200 \mathrm{mmHg}$. Therefore, the minimal extracorporeal blood volume will be about $70 \mathrm{ml}$, which is $10 \%$ of the blood volume of a $8.5 \mathrm{~kg}$ child. In the United States, similar dialyzers are available (Tables 1,3 ).

Characteristics of dialyzers for use in small children (up to $20 \mathrm{~kg}$ ) are given in Tables 1 and 3. To avoid backflow of 
dialysate during dialysis with low ultrafiltration rates, high-flux dialyzers should not be used. Also, dialyzers with large compliance are unsuitable for dialysis in small children. The best choice is a low-flux hollow-fiber dialyzer. An additional advantage of the hollow-fiber dialyzer is the relatively lower heparinazation needed compared with the plate dialyzers. If possible, matching the dialysis fluid to the patient's individual need is desirable. The ideal approach may be to vary the composition of the dialysate throughout dialysis, allowing progressive normalization of the extracellular fluid volume and composition. Dialysis may start with a low sodium level $(135 \mathrm{mmol} / 1)$ which is progressively increased throughout dialysis to $145 \mathrm{mmol} / 1$ [8]. This allows correction for osmolar shift for, as the blood urea nitrogen (BUN) osmolality decreases, the sodium osmolality increases. The use of bicarbonate-containing dialysate is advocated because it provides better hemodynamic stability during dialysis [9].

To insure maximum safety during ultrafiltration, a dialysis system equipped with a volumetric ultrafiltration control should be used. Although blood flow rates must be individually determined, blood flow rates of $5 \mathrm{ml} / \mathrm{kg}$ per min may provide efficient BUN clearances. Most dialysis systems will require adapted blood pumps to fit within the thin bloodlines.

\section{Management of dialysis}

The dialysis should be adjusted to the individual needs of the child as determined not only by the size of the patient but also by individual variations in dialysis tolerance. Small children weighing less than $8 \mathrm{~kg}$ are especially vulnerable because well adapted equipment is not always available and because their need for dialysis (nutrient intake) and ultrafiltration (fluid intake) is relatively high compared with older children. Because most often overefficient dialyzers and large extracorporeal blood volumes are used, adaptation of dialysis techniques are required to avoid severe complications.

In small children (less than $8 \mathrm{~kg}$ ), the priming fluid of the extracorporeal circuit is transfused into the patient. For the first dialysis or when the circulation of the child is unstable, the extracorporeal circuit should be primed with whole blood or $5 \%$ albumin. The risk of blood priming may be threefold: (1) the viscosity of the banked blood (hematocrit roughly $80 \%$ ) is higher than that of the patient resulting in an initial high circuit resistance; (2) due to the latter a higher than normal amount of heparinazation may be necessary in order to avoid clotting; (3) the potassium of the banked blood may exceed $20 \mathrm{mEq} / \mathrm{l}$. Therefore, a potassium load could potentially occur in a patient already at risk for hyperkalemia. In subsequent dialysis, with the patient in stable condition, normal saline or 5\% albumin is used as priming solution. Ultrafiltration should be carefully planned and excessive fluid loss should be replaced throughout dialysis. Volumetric control of ultrafiltration is usually approximate (only within $\pm 100 \mathrm{ml} / \mathrm{h}$ ). Therefore, continuous weight monitoring during dialysis is required. Besides ultrafiltration fluid losses, additional fluid losses may occur through nasogastric drainage, vomiting and di- arrhea. Intravenous infusion of saline, albumin and blood or oral food intake may change the patient's circulating and total body fluid volume. With the use of electronic weighing equipment, it is possible to monitor small changes in weight. Accurate weighing requires that weight reading is not affected by movements of the patient or by the dialysis equipment. If total fluid removed is less than $5 \%$ of body weight and the rate at which removal occurs is less that $0.2 \mathrm{ml} / \mathrm{kg}$ per $\mathrm{min}$, the procedure is relatively safe. If more fluid has to be removed, circulatory collapse may develop. Consequently, close supervision of the patient during ultrafiltration is required.

Agitation, vomiting and color changes often precede changes in vital signs. Critical changes in vital signs appear suddenly making continuous registration of pulse, respiration, blood pressure and body temperature (central and peripheral to gauge tissue perfusion) important.

Treatment of hypotension requires administration of $0.9 \%$ saline, $20 \%$ mannitol or $5 \%$ albumin. Accurate estimation of dry body weight is essential for assessment of the need for ultrafiltration. Percentile cards used to determine the ideal weight according to the child's height and build are often not adequate to assess dry body weight in a uremic infant. More accurate measurements of dry weight may be achieved by measurements of inulin distribution volume. Ultrafiltration should maintain inulin distribution volume between $22 \%$ and $29 \%$ [10].

To prevent hypotension if ultrafiltration in excess of $5 \%$ of body weight is required, infusion of mannitol at $1 \mathrm{~g} / \mathrm{kg}$ may be performed. To avoid accumulation, mannitol should be administered only once a week [11]. High sodium dialysate levels, maintained at a constant level or progressively increasing during dialysis; may be used to conserve plasma volume during ultrafiltration [12]. Both methods increase extracellular osmolality, improve extracellular fluid refilling from the intracellular space and maintain blood volume. This may also prevent dialysis dysequilibrium in some patients [13].

At the start of dialysis, if the extracorporeal circuit was primed with blood, the content of this system can be discarded at the end of the dialysis procedure. Otherwise the extracorporeal blood is transfused back into the patient. In small children with an extracorporeal blood volume of more than $10 \%$, back transfusion may produce circulatory overload. Therefore, this transfusion, has to be performed much slower than in older children; careful attention must also be given to heart rate and rhythm. Development of a gallop rhythm indicates circulatory overload and requires termination of the procedure. Withdrawal of blood from the patient to reduce blood volume may be necessary. Due to heat losses in children and the relatively slow blood flow rates of hemodialysis, attention to the temperature of the infant or small child is important. Increasing the dialysate temperature may be required in this setting.

General heparinization can be effected by administration of $20-50 \mathrm{U}$ heparin $/ \mathrm{kg}$ at the beginning of dialysis, followed by continuous infusion of $10-25 \mathrm{U} / \mathrm{kg}$ per hour. In children with a high risk of bleeding, this dose could be reduced to $10 \mathrm{U} / \mathrm{kg}$ per hour [14], or utilization of one of the newer more biocompatible dialyzers could allow one to dialyze without heparin. During the first few dialyses and 
following surgical procedures, assessment of coagulation is required; the heparin dose should to be adjusted to reach an activated clotting time between 100 and $200 \mathrm{~s}$ (Hemochrom, International Technidyne, Edison, N. J. USA).

When small children are dialyzed with single-needle systems, urea clearances will usually not exceed 4-5 $\mathrm{ml} / \mathrm{min}$ per $\mathrm{kg}$, because of low blood flows. However, efficient dialysis will be easily obtained because of the prolonged dialysis time $(4 \mathrm{~h})$ required to achieve adequate ultrafiltration in a safe way.

Although pediatric patients are usually dialyzed three times a week, very small children will need at least four dialyses per week. The increase of body fluid, if adequate nutrition is provided, will lead to circulatory overload when subsequent dialyses are not performed within $48 \mathrm{~h}$. If the time between dialyses has to be extended, restriction of fluid intake will be required.

To assess the adequacy of dialysis in infants and small children the benefit of urea kinetic modelling may be questioned. If urea clearance $(\mathrm{Kt} / \mathrm{U})$ is calculated from pre and post dialyses blood urea values, the need for dialysis may be underestimated. However, dialysis time will be largely determined by the requirement of ultrafiltration.

\section{Conclusion}

HD can be safely performed in infants and small children. Adaptation of materials and techniques to reduce the complications related to important changes in blood volume are required. Personnel with experience in dialysis of children and attention to detail can make it a practical therapy.

Acknowledgement. The authors would like to thank Ms. Sharon Doyle for her diligence in the preparation of this manuscript and the HD and intensive care nurses at both institutions for their excellent care of the children

\section{References}

1. Mauer SM, Lynch RE (1976) Haemodialysis techniques for infants and children. Pediatr Clin North Am 23: 843-856

2. Ahola T, Bjorkman H, Makela P (1972) The low weight groups and haemodialysis. Acta Paediatr Scand 61: 1 -6

3. Ehrich JHH, Rizzoni G, Brunner FP, Fassbinder W, Geerlings W, Mallick NP, Raine AEG, Selwood NH, Tufveson G (1992) Renal replacement therapy for end stage renal failure before 2 years of age. Nephrol Dial Transplant 7: $1171-1177$

4. United States Renal Data System 1991 Annual Data Report. VIII. (ESRD) in children 1991. Am J Kidney Dis 18: S2: $79-88$

5. Rutledge SL, Havens PL, Haymond MW, McLean RH, Kan JS, Brusilow SW (1990) Neonatal hemodialysis: effective therapy for the encephalopathy of inborn errors of metabolism. J Pediatr 116 : $125-128$

6. Mahan JD, Mauer SM, Nevins TE (1983) The Hickman catheter. A new haemodialysis access device for infants and small children. Kidney Int 24: 694-697

7. Pillion G, Maisin A, Macher MA, Bourquelot P, Loirat C (1988) Hickman catheter for HD in paediatric patients. Pediatr Nephrol 2: 318-319

8. Vries PMJM de, Olthof CG, Solf A, Schuenemann B, Oe PL, Quellhorst E, Schneider H, Donker AJM (1991). Fluid balance during HD and hemofiltration: the effect of dialysate sodium and a variable ultrafiltration rate. Nephol Dial Transplant 4: 257-263

9. Leunissen KML, Hooff JP van (1988) Acetate or bicarbonate for haemodialysis. Nephrol Dial Transplant 3:1-7

10. Leroy D, Dechaux D, Guest G, Broyer M, Sachs C (1985) Extracellular volume and blood pressure in 82 haemodialysed children. Proc Eur Dial Transplant Assoc 22: 847-850

11. Swamy AP, Cestero RVM (1979) Mannitol and maintenance HD. Artif Organs 3: 116-118

12. Kouw PM, Olthof CG, Gruteke P, Vries PMJM de, Meijer JH, Oe PL, Schneider H, Donker AJM (1991) Influence of high and low sodium dialysis on blood volume preservation. 6: 876-880

13. Rosa AA, Shideman J, McHugh R, Duncan D, Kjellstrand CM (1981) The importance of osmolality fall and ultrafiltration rate on hemodialysis side effects: influence of intravenous mannitol. Nephron 27: 134-141

14. Geary DF, Gajaria M, Fryer-Keeze S, Willemsen J (1991) Low dose and heparin free hemodialysis in children. Pediatr Nephrol 5: $220-224$

\section{Literature abstract}

Am J Physiol (1993) 265: (Renal Fluid Electrolyte Physiol 34): F1 -F14

\section{The growth hormone insulin-like growth factor axis in kidney revisited}

\section{Marc R. Hammerman and Steven B. Miller}

Studies characterizing actions of growth hormone (GH) and insulinlike growth factors (IGF) in kidneys of adult and developing animals and humans have provided a good deal of insight into the functions of these peptides. Although certain of the actions may be mediated directly by GH, most appear to result from effects of GH to increase levels of circulating IGF or IGF produced in kidney. In addition to $\mathrm{GH}$, epidermal growth factor (EGF) enhances the renal synthesis of IGF-I. Enhancement of renal IGF-I expression is GH independent in compensatory hypertrophy. Stimulation of kidney IGF-I production also occurs in diabetes mellitus. Renal IGF-I production is elevated in these settings in the absence of changes in circulating IGF-I, consistent with a causative role of renal IGF-I for the accompanying increased glomerular filtration rate and kidney growth. Actions of IGF in kidney are initiated following binding of peptides to specific receptors. Receptor number may be altered during compensatory growth and in diabetes mellitus. In addition to IGF, several IGF binding proteins (IGFBP) are produced in kidney and are likely to both inhibit and enhance the actions of IGF in different circumstances through sequestration of peptides and regulation of peptide interactions with their receptors. Administration of IGF-I to rats following acute ischemic injury hastens the recovery of normal renal function and accelerates the regeneration of the damaged proximal tubular epithelium. IGF-I increases the glomerular filtration rate in humans with normal and reduced functional kidney mass. These findings establish the potential for use of this peptide as a therapeutic agent in the settings of acute and chronic renal failure. 